\title{
Genetic Relationships Among Populations of Gibberella zeae from Barley, Wheat, Potato, and Sugar Beet in the Upper Midwest of the United States
}

\author{
R. R. Burlakoti, S. Ali, G. A. Secor, S. M. Neate, M. P. McMullen, and T. B. Adhikari
}

Department of Plant Pathology, North Dakota State University, 306 Walster Hall, Fargo 58105.

Accepted for publication 2 June 2008.

\begin{abstract}
Burlakoti, R. R., Ali, S., Secor, G. A., Neate, S. M., McMullen, M. P., and Adhikari, T. B. 2008. Genetic relationships among populations of Gibberella zeae from barley, wheat, potato, and sugar beet in the upper Midwest of the United States. Phytopathology 98:969-976.

Gibberella zeae, a causal agent of Fusarium head blight (FHB) in wheat and barley, is one of the most economically harmful pathogens of cereals in the United States. In recent years, the known host range of $G$. zeae has also expanded to noncereal crops. However, there is a lack of information on the population genetic structure of G. zeae associated with noncereal crops and across wheat cultivars. To test the hypothesis that $G$. zeae populations sampled from barley, wheat, potato, and sugar beet in the Upper Midwest of the United States are not mixtures of species or $G$. $z e a e$ clades, we analyzed sequence data of G. zeae, and confirmed that all populations studied were present in the same clade of $G$. zeae. Ten variable number tandem repeat (VNTR) markers were used to determine the genetic structure of $G$. zeae from the four crop populations. To examine the effect of wheat cultivars on the pathogen populations, 227 strains were sampled from 10 subpopulations according to wheat cultivar types.
\end{abstract}

ABSTRACT
The VNTR markers also were used to analyze the genetic structure of these subpopulations. In all populations, gene $(H=0.453$ to 0.612$)$ and genotype diversity $(G D=>0.984)$ were high. There was little or no indication of linkage disequilibrium (LD) in all G. zeae populations and subpopulations. In addition, high gene flow $(\mathrm{Nm})$ values were observed between cereal and noncereal populations $(\mathrm{Nm}=10.69)$ and between FHB resistant and susceptible wheat cultivar subpopulations $(\mathrm{Nm}=$ 16.072), suggesting low population differentiation of G. zeae in this region. Analysis of molecular variance also revealed high genetic variation $(>80 \%)$ among individuals within populations and subpopulations. However, low genetic variation $(<5 \%)$ was observed between cereal and noncereal populations and between resistant and susceptible wheat subpopulations. Overall, these results suggest that the populations or subpopulations are likely a single large population of G. zeae affecting crops in the upper Midwest of the United States.

Additional keywords: Beta vulgaris, Fusarium graminearum, Hordeum vulgare, population genetics, Solanum tuberosum, Triticum aestivum.
Gibberella zeae (anamorph: Fusarium graminearum) causes Fusarium head blight (FHB) in wheat and barley, and is an economically harmful cereal pathogen worldwide $(32,47)$. In the Northern Great Plains, FHB resulted in $\$ 1.65$ billion in losses from 1998 to 2000 (42). G. zeae produces several mycotoxins that threaten human and animal health $(14,28)$. The fungus has both sexual and asexual stages (8). The sexual stage produces ascospores, and the asexual stage produces macroconidia. Both airborne ascospores and conidia may play important roles for the disease development in fields $(6,29)$.

Understanding the genetic diversity and the population biology of a plant pathogen is essential to predict disease epidemics in agricultural ecosystems and to deploy disease management strategies more effectively (31). For example, high genetic variation within a small area may indicate that sexual reproduction is occurring frequently in that field. This may allow the pathogen to adapt quickly in various environments $(8,36)$. Gene flow can predict the ability to spread genes and genotypes throughout a geographic area (52). If gene flow between populations is limited, then disease management strategies, such as regional resistance gene deployment, crop rotation, and fungicide applications targeting local populations are more likely to be successful (30).

Corresponding author: T. B. Adhikari; E-mail address: tika.adhikari@ndsu.edu

doi:10.1094/PHYTO-98-9-0969

(c) 2008 The American Phytopathological Society
Thus, when screening and developing resistant cultivars, plant pathologists and plant breeders need to consider the local genotypes or pathotypes as well as the possibility of new genotypes that could migrate into an area.

Molecular markers, such as random amplified polymorphic DNA $(15,35,59)$, restriction fragment length polymorphism $(20,21)$, amplified fragment length polymorphism $(2,50,62)$, intersimple sequence repeat (38), and sequence related amplified polymorphism (18), have been used to investigate the diversity in G. zeae populations from wheat-growing regions of the world. Recently, the variable number tandem repeat (VNTR) markers have been developed and used for genetic studies of G. zeae (55). VNTR marker analysis is a sensitive, rapid, and cost-effective method to measure genetic variability of organisms (27). The genetic structure of $G$. zeae populations analyzed so far has been mainly from wheat. $G$. zeae has been reported to cause disease in noncereal crops such as dry bean (7), potato (3), soybean (9), and sugar beet (23). G. zeae populations collected from potato and sugar beet were found to infect wheat and produce several mycotoxins (11). However, the genetic structure of $G$. zeae populations from potato and sugar beet has not been fully investigated.

Three hard red spring wheat (HRSW) cultivars (e.g., Alsen, Steele-ND, and Glenn) that are moderately resistant to FHB, have been developed by North Dakota State University (NDSU). Alsen was developed by incorporating resistance from 'Sumai 3' (19, 33). The source of FHB resistance in Steele-ND was believed to be derived from Triticum dicoccoides, while Glenn was developed 
from a cross between the 'Sumai 3' derivative line and Steele-ND (33). Among them, Alsen was a leading HRSW cultivar in North Dakota and accounted for $\approx 29$ and $23 \%$ of the planted acreage during 2004 and 2005, respectively (57). More recently, Glenn became the dominant variety grown on $20.9 \%$ of the acres in 2007 (57). However, little is known about the influence of these moderately resistant cultivars on the diversity of G. zeae.

We hypothesize that substantial genetic exchange has occurred between populations of $G$. zeae across cereal (barley and wheat) and noncereal (potato and sugar beet) hosts, and across wheat cultivars. The specific objectives of this study were to (i) perform sequence analysis to ensure that all strains studied belong to the same clade of $G$. zeae; (ii) determine the genetic structure of $G$. zeae populations from barley, wheat, potato, and sugar beet using VNTR markers; and (iii) assess the influence of FHB resistant and susceptible wheat cultivars on the genetic structure of G. zeae from wheat. Collectively, a study on the genetic structure of $G$. zeae populations associated with different crop species and wheat cultivars should provide insight into how to best manage FHB in cereals and G. zeae associated with potato and sugar beet in field and in storage.

\section{MATERIALS AND METHODS}

Collection and isolation of the fungus. FHB-infected heads of 10 HRSW cultivars (Table 1) were collected at the early to late stage (Feekes 11.1 and 11.2) (25) from three locations (Carrington, Langdon, and Minot) in North Dakota during 2004 and 2005. Thirty symptomatic heads of each cultivar were collected randomly within a $61 \times 2 \mathrm{~m}^{2}$ dry land plot area of each cultivar at each location. FHB-infected barley heads were collected from six-row (cv. Robust), and two-row (cv. Conlon) barley from Fargo, ND, during 2004 and 2005. Thirty symptomatic barley heads from each of both cultivars were collected at random within a dry land plot area of $30 \times 50 \mathrm{~m}^{2}$.

The strains of $G$. zeae from potato were recovered from processing potatoes collected from storage facilities that represent the three major irrigated potato production areas of North Dakota and Minnesota (16). Each sampling region represents a processing potato factory district and supplies the raw product for one of the three factories. The three districts are Jamestown and Grand Forks, ND, and Park Rapids, MN. Tubers with external Fusarium dry rot visual symptoms were collected randomly from storage bins in each of the three areas (Jamestown, $n=325$; Grand Forks, $n=240$; Park Rapids, $n=570$ ) and brought to the laboratory for further processing. Each tuber was cut longitudinally, and those with internal symptoms consistent with Fusarium dry rot were tested for the presence of Fusarium. In all, 119 strains of G. zeae were recovered (36 strains from Jamestown, 14 from Grand Forks, and 69 from Park Rapids). Among these strains of G. zeae, a subset of 38 strains (19 strains from Jamestown, 5 from Grand Forks, and 14 from Park Rapids,) was chosen randomly and analyzed in this study.

Sugar beet samples exhibiting symptoms of yellowing, wilting, and vascular discoloration of the tap root were collected from three commercial fields in the sugar beet production areas of west-central Minnesota near the towns of Fossum, Georgetown, and Sabin. From these samples, 11 strains of G. zeae from Fossum, 9 from Georgetown, and 1 from Sabin were analyzed in this study. The four strains of G. zeae previously collected from sugar beet grown near Fisher in western Minnesota were provided by C. Windels, University of Minnesota, Crookston, and an additional two strains of $G$. zeae from sugar beet collected in western Minnesota were obtained from L. E. Hanson, USDAARS, CO.

To isolate the fungus, infected kernels of wheat and barley, and either infected potato tuber or sugar beet tap root tissues were selected. Each diseased kernel, tuber, or taproot was surface sterilized in a 5\% sodium hypochlorite solution for 1 to $2 \mathrm{~min}$, rinsed in sterile distilled water and transferred to Komada media (24). Pure cultures of the fungus were transferred to half-strength potato dextrose agar (PDA) (100 $\mathrm{g}$ of potato, $10 \mathrm{~g}$ of dextrose, and $10 \mathrm{~g}$ of agar per liter of water). To obtain a single spore culture, an approximately 1-cm block from a 3- to 4-day-old PDA culture of each strain was removed, inverted, and then rubbed lightly across the surface of a water agar plate. After observation under a dissecting microscope, a piece of water agar having a single conidium was taken from the agar plate and transferred onto a fresh half-strength PDA, and grown for 4 to 5 days under alternating $12 \mathrm{~h}$ light and dark at $22 \pm 1{ }^{\circ} \mathrm{C}$. Single-spore strains were prepared for all populations analyzed in this study.

Identification of $\boldsymbol{G}$. zeae strains. Morphological characteristics $(41,53)$ and $G$. zeae specific primers (44) were used to identify the fungal strains, as described previously (11). Briefly, we examined morphological characteristics such as absence of microconidia, shape, size, septa, and curvature of macroconidia, basal and apical cells of macroconidia, profuse aerial mycelium and production of carmine red color under the surface of PDA, and formation of perithecia on carnation leaf agar. In all, 320 strains of $G$. zeae from wheat $(n=227$ strains), barley $(n=28$

TABLE 1. Summary information for 227 strains of Gibberella zeae collected from 10 wheat cultivars in North Dakota

\begin{tabular}{|c|c|c|c|c|c|c|c|}
\hline \multirow[b]{2}{*}{ Cultivars } & \multirow[b]{2}{*}{ Source $^{\mathrm{a}}$} & \multirow[b]{2}{*}{ Year released $^{\mathrm{b}}$} & \multirow{2}{*}{$\begin{array}{l}\text { Reaction to Fusarium } \\
\text { head blight }^{\mathrm{c}}\end{array}$} & \multicolumn{3}{|c|}{ Number of strains sampled at location } & \multirow{2}{*}{$\begin{array}{c}\text { Total number } \\
\text { by location }\end{array}$} \\
\hline & & & & Carrington & Langdon & Minot & \\
\hline \multicolumn{8}{|c|}{ Resistant cultivars } \\
\hline Alsen & NDSU & 2000 & MR & 8 & 18 & 10 & 36 \\
\hline Glenn & NDSU & 2005 & MR & 10 & 8 & 10 & 28 \\
\hline Steele ND & NDSU & 2004 & MR & 17 & 9 & 10 & 36 \\
\hline Subtotal & & & & 35 & 35 & 30 & 100 \\
\hline \multicolumn{8}{|c|}{ Susceptible cultivars } \\
\hline Briggs & SDSU & 2002 & $\mathrm{~S}$ & 10 & 8 & - & 18 \\
\hline Dapps & NDSU & 2003 & MS & 9 & 8 & - & 17 \\
\hline Granite & WestBred & 2002 & MS & 8 & 9 & - & 17 \\
\hline Gunner & AgriPro & 1995 & I & 8 & 10 & - & 18 \\
\hline Knudson & AgriPro & 2001 & $\mathrm{I}$ & 9 & 10 & - & 19 \\
\hline Norpro & AgriPro & 1999 & $\mathrm{~S}$ & 9 & 7 & - & 16 \\
\hline Saturn & N. Star G. & 2003 & $\mathrm{~S}$ & 9 & 13 & - & 22 \\
\hline Subtotal & & & & 62 & 65 & & 127 \\
\hline Total & & & & 97 & 100 & 30 & 227 \\
\hline
\end{tabular}

a Origin of wheat cultivars: NDSU = North Dakota State University, SDSU = South Dakota State University, N. Star G. = North Star Genetics (49).

b According to Ransom et al. (49).

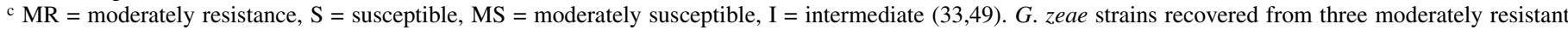
cultivars were grouped into resistant subpopulations while the strains recovered from susceptible, moderately susceptible, and intermediate cultivars were grouped into susceptible subpopulations. 
strains), potato ( $n=38$ strains), and sugar beet ( $n=27$ strains) were analyzed in this study. All strains analyzed in this study were deoxynivalenol (DON) producers (10). A G. zeae reference strain (NRRL 31084) was provided by K. O'Donnell, the U.S. Department of Agriculture (USDA), Agricultural Research Service, National Center for Agricultural Utilization Research, Peoria, IL, and obtained under a permit from the USDA-APHIS. For long-term storage, mycelial plugs were preserved in $30 \%$ glycerol and maintained at $-80^{\circ} \mathrm{C}$.

DNA sequencing. DNA sequencing was used to establish that strains sampled belong to clade 7 of $G$. zeae. A subset of 32 strains of putative $G$. zeae were randomly selected to represent $\approx 10 \%$ of each population (4 strains from barley, 18 from wheat, 5 from potato, and 5 from sugar beet) and sequenced. Qiagen DNeasy Plant Mini Kit (Qiagen Inc., Valencia, CA) was used to extract genomic DNA from each strain. The portions of phosphate permease (PHO) and translation elongation factor-1 $\alpha$ (TEF) genes were amplified by polymerase chain reaction (PCR) primer sets, PHO1 $\times$ PHO6 and EF1T $\times$ EF2T, respectively (45). Each PCR reaction $(25 \mu \mathrm{l})$ consisted of $2.0 \mu \mathrm{l}$ of $25 \mathrm{mM} \mathrm{MgCl}_{2}, 2.0 \mu \mathrm{l}$ of $10 \times$ PCR buffer, $0.5 \mu \mathrm{l}$ of $10 \mathrm{mM}$ dNTP mix, $1.5 \mu \mathrm{l}$ of Taq polymerase $(5$ units $/ \mu \mathrm{l})$, and $1 \mu \mathrm{l}$ of each primer $(1 \mu \mathrm{M})$. Thermal cycling conditions were 40 cycles, $94^{\circ} \mathrm{C}$ for $30 \mathrm{~s}, 52^{\circ} \mathrm{C}$ for $30 \mathrm{~s}$, and $72^{\circ} \mathrm{C}$ for $1 \mathrm{~min}$. Amplified products were purified using the QIAquick PCR purification kit (Qiagen Inc.), and 2 to $3 \mu \mathrm{l}$ of purified product was visualized in a $2 \%$ (wt/vol) agarose gel (Sigma-Aldrich, Inc., St. Louis, MO). Sequencing was performed at the Molecular Cloning Laboratories (MCLAB) DNA sequencing service (San Francisco, CA) and the High Throughput Genotyping Center (HTGC), North Dakota State University
(Fargo, ND). Sequencing of these genes was performed in both sense and antisense directions.

Sequence analysis. The sequence data were edited manually using the Staden Package (54). The raw trace data were processed using the Pregap4 and contigs were edited using the Gap4 program (54). Both forward and reverse sequences of each strain were aligned in MultAlin (12) to identify the overlap, and a single sequence was prepared for each strain. Sequence identity of the two genes across the 32 representative strains of $G$. zeae was confirmed by conducting a BLAST search (4) in GenBank (the National Center for Biotechnology Information). To test whether or not our strains can be placed in clade 7 of G. zeae, sequence data of seven reference strains (NRRL28336, NRRL6394, NRRL5883, NRRL28063, NRRL13383, NRRL31084, and NRRL34079) within the $F$. graminearum clade 7 and other phylogenetically distinct species within the $F$. graminearum clade, and three species of Fusarium such as $F$. pseudograminearum, $F$. culmorum, and $F$. cerealis were downloaded from previous studies $(45,46)$ and used as reference sequences. The intergenic spacer between the phosphate permease 1 and 2 genes was trimmed from our sequence data using GenDoc (43) to remove phylogenetic bias. Phylogenetic trees were constructed using phylogenetic analysis using parsimony (PAUP*) version $4.0 \mathrm{~b} 10$ (56). Heuristic searches were used for maximum parsimony analyses. Bootstrap analysis was performed with 1,000 pseudoreplicates and $60 \%$ consensus levels. DNA sequence data of the 32 representative strains of $G$. zeae were deposited in GenBank (accession nos. EU589624 to EU589687) and the phylograms were submitted to TreeBase (study accession no. 52077 and matrix accession nos. M3891 and M3892).
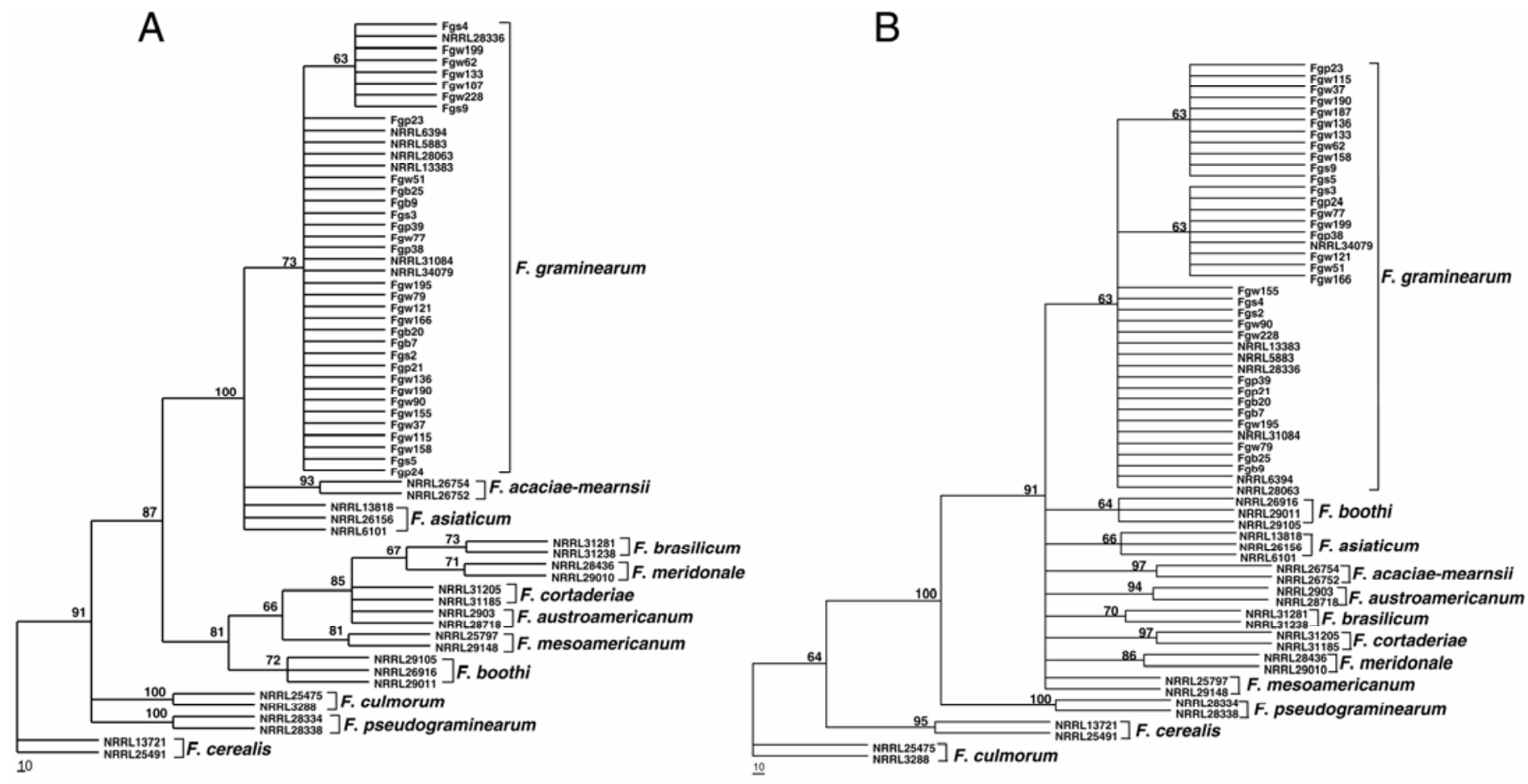

Fig. 1. Maximum parsimony phylogram of Gibberella zeae (anamorph: Fusarium graminearum) strains from this study and strains of Fusarium spp. from O'Donnell et al. $(45,46)$ generated using sequences of phosphate permease and phosphate permease 2 genes (PHO1 $\times$ PHO6) and translation elongation factor-1 $\alpha$ $($ EF1T $\times$ EF2T) genes. A, Phylogram generated using sequence from phosphate permease gene. B, Phylogram generated using sequence from translation elongation factor- $1 \alpha$ gene. The strains Fgb7, Fgb9, Fgb20, and Fgb25 were from barley; strains Fgw37, Fgw51, Fgw62, Fgw77, Fgw79, Fgw90, Fgw115, Fgw121, Fgw133, Fgw136, Fgw155, Fgw158, Fgw166, Fgw187, Fgw190, Fgw195, Fgw199, and Fgw228 were from wheat; strains Fgp21, Fgp23, Fgp24, Fgp38, and Fgp39 were from potato; strains Fgs2, Fgs3, Fgs4, Fgs5, and Fgs9 were from sugar beet. All the strains naming with NRRL were downloaded from the National Center for Biotechnology Information (NCBI) website deposited by O'Donnell et al. $(45,46)$. Seven reference strains such as NRRL28336, NRRL6394, NRRL5883, NRRL28063, NRRL13383, NRRL31084, and NRRL34079 are F. graminearum (clade 7); NRRL26754 and NRRL26752 are F. acaciae-mearnsii; NRRL13818, NRRL26156, and NRRL6101 are F. asiaticum; NRRL31281 and NRRL31238 are F. brasilicum; NRRL28436 and NRRL29010 are F. meridonale; NRRL31205 and NRRL31185 are $F$. cortaderiae; NRRL2903 and NRRL28718 are $F$. austroamericanum; NRRL25797 and NRRL29148 are $F$. mesoamericanum; NRRL29105, NRRL26916, and NRRL29011 are F. boothi; NRRL25475 and NRRL3288 are F. culmorum; NRRL28334 and NRRL28338 are F. pseudograminearum; NRRL13721 and NRRL25491 are F. cerealis $(45,46)$. 
VNTR marker analysis. Genomic DNA of each strain was extracted, as described previously (13). In addition, genomic DNA of the 32 strains of G. zeae (Fig. 1) and reference strain NRRL 31084 of $G$. zeae also was extracted using the Qiagen DNeasy Plant Mini Kit (Qiagen Inc.). DNA extracted with these two independent methods was used to compare and confirm VNTR marker repeatability and to determine PCR robustness. Each DNA sample was quantified with a fluorometer and adjusted to a final concentration of $10 \mathrm{ng} / \mu \mathrm{l}$. All VNTR polymorphisms were verified by two independent PCR assays with negative controls (primer and water) and a positive control using reference strain NRRL 31084 of G. zeae. Unless stated otherwise, all PCR regents were purchased from the Promega Corporation (Madison, WI), and primers were synthesized by Integrated DNA Technologies (IDT) Inc. (Coralville, IA).

The genetic structure of the four populations of G. zeae was analyzed using the 10 VNTR primers (55). All PCR reactions and conditions were used as described previously (55) with some modifications. Each PCR reaction with a final volume of $10 \mu \mathrm{l}$ consisted of $4 \mu \mathrm{l}$ of sterile ultrapure water, $1.0 \mu \mathrm{l}$ of $10 \times \mathrm{PCR}$ buffer, $1.0 \mu \mathrm{l}$ of $25 \mathrm{mM} \mathrm{MgCl} 2,0.25 \mu \mathrm{l}$ of $10 \mathrm{mM}$ dNTP mix, $0.75 \mu \mathrm{l}$ of $\mathrm{Taq}$ polymerase ( 5 units/ $\mu \mathrm{l}), 1 \mu \mathrm{l}$ of $2 \mu \mathrm{M}$ each forward and reverse primer, and $1 \mu \mathrm{l}$ of fungal genomic DNA $(10 \mathrm{ng} / \mu \mathrm{l})$. PCR reactions were conducted using a PTC-100 Thermal Cycler (MJ Research, Watertown, MA) at standard amplifications of initial denaturation at $95^{\circ} \mathrm{C}$ for $2 \mathrm{~min}$, followed by 30 cycles at $94^{\circ} \mathrm{C}$ for $30 \mathrm{~s}, 58^{\circ} \mathrm{C}$ for $1 \mathrm{~min}$, and $72^{\circ} \mathrm{C}$ for $1 \mathrm{~min}$. The final extension temperature was at $72^{\circ} \mathrm{C}$ for $10 \mathrm{~min}$ before cooling to $4^{\circ} \mathrm{C}$. DNA fragments were analyzed on $6 \%$ urea nondenaturing polyacrylamide gels and run in $0.5 \times$ TBE buffer $(0.09 \mathrm{M}$ Trisborate and $0.002 \mathrm{M}$ EDTA), as described previously (51). To visualize VNTR amplicons, $20 \mu \mathrm{l}$ of $10 \mathrm{mg} / \mathrm{ml}$ ethidium bromide was added to the lower reservoirs, and the gel was pre-run at 350 volts for $1 \mathrm{~h}$. After prestaining the gel, $10 \mu \mathrm{l}$ of amplified PCR product mixed with $3 \mu$ of $2 \%$ STR loading dye was loaded in each well. The gel was run at $350 \mathrm{~V}$ for $1.5 \mathrm{~h}$, and photographs were taken in a Fluorochem 2200 Image system (Alpha Innotech Corp., San Leandro, CA). Either the 50- or 100-bp DNA ladder (Invitrogen Corporation, Carlsbad, CA) was used to estimate size of the VNTR alleles in this study. In particular, the 50-bp ladder consists of 16 blunt-ended fragments ranging in length from 50 to $800 \mathrm{bp}$, at 50-bp, while the 100-bp ladder consists of 15 bluntended fragments ranging in length from 100 to $1,500 \mathrm{bp}$ at 100-bp increments (Invitrogen). For each VNTR marker, alleles with the same DNA band size were considered to be the same allele.

Population analysis. The G. zeae strains were classified into a population according to host type, such as barley, wheat, potato, and sugar beet, and into crop class type, such as cereal population from barley and wheat and noncereal population from potato and sugar beet. The wheat population was further partitioned into the 10 subpopulations based on cultivar types (e.g., Alsen, Glenn, Gunner, and Steele-ND). In addition, strains collected from the three moderately resistant FHB wheat cultivars Alsen, Glenn, and Steele-ND, were combined to represent a "resistant subpopulation" and strains collected from the other seven wheat cultivars were combined to represent a "susceptible subpopulation."

Data generated from the 10 VNTR loci were combined to identify a multilocus genotype $(G)$. All analyses were performed from clone-corrected data. Allele frequency was calculated for a single locus, and determined for each allele. Allele frequencies, gene diversity $(H)(39,40)$, Nei's unbiased genetic identity $(I)$, genetic distance $(D)(40)$, and the overall estimate of population genetic differentiation $(F$ st) and gene flow $(\mathrm{Nm})$ were calculated in POPGENE version $1.32(61) . H$ is a function of the number and frequencies of alleles at each locus and was estimated in the total population $\left(H_{\mathrm{T}}\right)$ and within population $\left(H_{\mathrm{S}}\right)(39,40)$. Genotype diversity $(G D)$ and multilocus linkage disequilibrium (LD) were calculated by Multilocus 1.3 software (1). $G D$, the prob- ability that two individual strains taken at random have different genotypes, was calculated by $(n / n-1)\left(1-\sum p i^{2}\right)$, where $p i$ is the frequency of the $i$ th genotype and $n$ is the number of individuals sampled (1). The LD measures the nonrandom association of alleles at different gene loci in a population. The test of significance was determined by using 1,000 randomizations in all populations and subpopulations.

The analysis of molecular variance (AMOVA) and the determination of pair-wise population genetic differentiation $(F \mathrm{st})$ and gene flow $(\mathrm{Nm})$ were calculated by GENALEX 6 (48). Fst is the ratio of the variance among populations relative to the total variance. $\mathrm{Nm}$ was calculated based on $F$ st as $N m=0.5[(1 / F \mathrm{st})-$ 1]. AMOVA (17) was performed to determine the genetic variation in populations from four hosts and in subpopulations from 10 wheat cultivars. The variance was partitioned into covariance components to estimate genetic variability into three levels. Covariance components used to calculate three $\Phi$ fixation indices $\left(\Phi_{\mathrm{PR}}, \Phi_{\mathrm{RT}}\right.$, and $\left.\Phi_{\mathrm{PT}}\right)$ and their levels of significance $(P<0.05$ or 0.01 ) were determined using 1,000 permutations (17). Variance was partitioned into variation between cereal and noncereal, variation among populations within cereal or noncereal, and variation of individuals within each population. Variation for subpopulations was partitioned into variation between a resistant and susceptible subpopulation, variation among cultivar subpopulations within resistant or susceptible subpopulation, and variation of individuals within cultivar subpopulations.

\section{RESULTS}

Sequence analysis. Sequence data of the PHO (799 characters) and TEF (625 characters) genes were obtained from 32 representative strains of $G$. zeae from barley, wheat, potato, and sugar beet. Maximum parsimony analysis revealed that all 32 strains belonged to clade 7 of G. zeae (Fig. 1A and B). The bootstrap values ranged from 63 to $100 \%$ for both PHO and TEF genes.

Genetic structure of $G$. zeae populations. The 10 VNTR markers generated 41 alleles, and the number of alleles at each locus varied from three to five (data not shown). The allele sizes ranged from 155- to 298-bp. Eight of the ten loci were polymorphic in the barley population, while all loci were polymorphic in the potato, sugar beet, and wheat populations. Gene diversity $(H)$ among four populations of $G$. zeae ranged from 0.453 (barley) to 0.612 (wheat) (Table 2). Both $G$ and $G D$ (0.984 to 0.998) values were high in all populations (Table 2). Among the 320 G. zeae strains analyzed, 253 distinct genotypes were identified.

The LD values were very low and varied from 0.003 to 0.041 in all populations (Table 2). Except for the barley population, all LD values were significant $(P<0.01)$. The overall estimated $D$ value between cereal and noncereal populations was 0.131. Pair-wise comparisons of $D$ across the four $G$. zeae populations ranged from 0.046 (potato and sugar beet populations) to 0.179 (wheat and potato populations) (Table 3 ). The overall estimated $F$ st and $\mathrm{Nm}$ values between cereal and noncereal populations were 0.044 and 10.69 , respectively. The potato and sugar beet population pair showed the highest $\mathrm{Nm}$ value $(\mathrm{Nm}=30.160)$ while the barley and potato population pairs showed the lowest $\mathrm{Nm}$ (4.110) (Table 3). AMOVA revealed low (4 to 6\%) genetic variation between the cereal population and the noncereal population and among populations within cereal or noncereal. In contrast, high (90\%) genetic variation was observed among individuals within populations (Table 4). AMOVA were statistically significant $(P<0.01)$.

Genetic structure of $G$. zeae spring wheat subpopulations. $H$ values for the 10 wheat cultivar subpopulations ranged from 0.420 (Gunner subpopulation) to 0.561 (Glenn subpopulation) (Table 5). Alsen, Glenn, and Steele-ND subpopulations had relatively higher $H$ values as compared to other subpopulations. A high $G D$ value was observed across 10 wheat cultivar subpopu- 
lations, ranging from 0.935 (Saturn subpopulation) to 0.985 (Steele-ND subpopulation). Except for the Granite (0.180), Dapps (0.200), and Knudson (0.240) subpopulations (Table 5), the LD estimates of the other wheat subpopulations were low, yet these values were statistically significant $(P<0.05)$.

The overall estimate of $N m$ and $D$ values between the resistant and susceptible subpopulations were 16.072 and 0.087 , respectively. Fst was low (0.030), suggesting that the resistant and susceptible subpopulations were similar. AMOVA showed a $1 \%$ genetic variation $(P<0.05)$ between resistant and susceptible subpopulations (Table 6). Genetic variation was 17 and $82 \%(P<$ 0.01 ) among subpopulations within the resistant or susceptible group and among individuals within subpopulations, respectively.

\section{DISCUSSION}

Our results indicated G. zeae populations from barley, wheat, potato, and sugar beet are genetically quite similar and are placed in clade 7 of $G$. zeae. In this respect, G. zeae populations from four crops were found to be present in the same clade of G. zeae studied in other regions $(45,62)$. Population analysis showed strong evidence for high genetic diversity and gene flow and low genetic differentiation among populations and subpopulations, indicating relatively high genetic exchange among them to maintain a single large population.
We observed high values for $H$ and $G D$ in all $G$. zeae populations and subpopulations analyzed. In addition, few identical genotypes of $G$. zeae were sampled from the same wheat subpopulation collected from the same location and year (data not shown). Intriguingly, higher percentages of distinct genotypes were found in potato and sugar beet populations compared with wheat populations. One possible explanation for the highly diverse genotypes found in potato and sugar beet populations could be the effect of sampling. The fungal strains from potato and sugar beet were more likely admixed because they were collected from large potato and sugar beet storage bins.

Our data showed LD estimates were low in all populations and in most subpopulations, although most of them differed significantly from zero. These results suggest that random mating occurred in all four populations and most wheat subpopulations. Our results correspond with previous studies $(50,62)$ that reported low LD values in $G$. zeae populations in the United States. In contrast, Gale et al. (20) observed significant LD in subpopulations within single, interbreeding populations of $G$. zeae in China. In this study, we observed higher LD values in three wheat subpopulations (e.g., Dapps, Granite, and Knudson) compared to other subpopulations. Although possible mechanisms such as genetic drift, population admixture, and sample size might have been responsible for deviation in gametic equilibria $(36,37)$, further epidemiological studies are needed to collect relatively

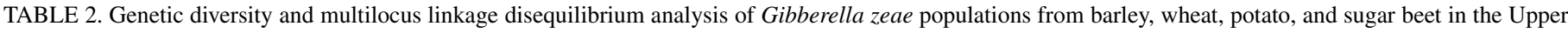
Midwest of the United States

\begin{tabular}{|c|c|c|c|c|c|}
\hline Population & $n^{\mathrm{a}}$ & $G^{\mathrm{b}}$ & $G D^{\mathrm{c}}$ & $H^{\mathrm{d}}$ & $\mathrm{LD}^{\mathrm{e}}$ \\
\hline Barley & 28 & 22 & 0.984 & 0.453 & 0.003 \\
\hline Wheat & 227 & 169 & 0.997 & 0.612 & $0.021 * * \mathrm{f}$ \\
\hline Potato & 38 & 37 & 0.998 & 0.585 & $0.025 * *$ \\
\hline Sugar beet & 27 & 25 & 0.997 & 0.540 & $0.041 * *$ \\
\hline Total & 320 & 253 & & & \\
\hline
\end{tabular}

a Sample size $(n)$.

b Number of distinct genotypes $(G)$.

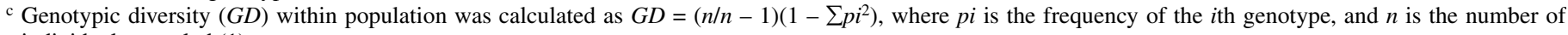
individuals sampled (1).

${ }^{\mathrm{d}}$ Gene diversity $(H)(40)$ within populations was calculated based on the 10 variable number tandem repeat loci from clone-corrected data.

e The measure of multilocus linkage disequilibrium (LD) calculated from clone-corrected data (1).

f $* *$ Indicates significant at $P<0.01$

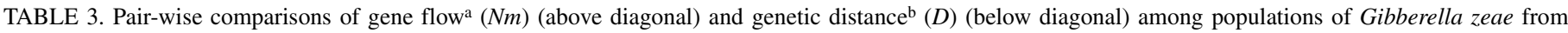
barley, wheat, potato, and sugar beet in the Upper Midwest of the United States

\begin{tabular}{|c|c|c|c|c|}
\hline Population & Barley & Wheat & Potato & Sugar beet \\
\hline Barley & $\ldots$ & 5.240 & 4.110 & 5.618 \\
\hline Wheat & 0.143 & $\ldots$ & 5.126 & 5.734 \\
\hline Potato & 0.172 & 0.179 & $\ldots$ & 30.160 \\
\hline Sugar beet & 0.121 & 0.155 & 0.046 & $\ldots$ \\
\hline
\end{tabular}

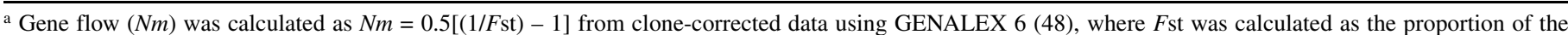
variance among populations relative to the total variance. Probability of obtaining equal or lower $F$ st value was determined by 1,000 randomizations by permuting individuals among populations.

b Nei's unbiased genetic distance $(D)$ was analyzed from clone-corrected data (40).

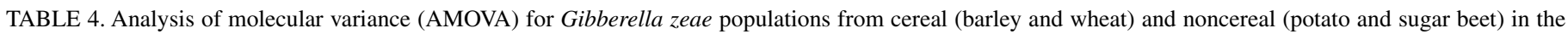
Upper Midwest of the United States

\begin{tabular}{|c|c|c|c|c|c|}
\hline Hierarchical analysis ${ }^{\mathrm{a}}$ & df & Estimated variance & Variation $(\%)$ & $\Phi^{\mathrm{b}}$ & $P$ value ${ }^{c}$ \\
\hline Between cereals and noncereals (ФRT) & 1 & 0.126 & 4 & 0.038 & 0.001 \\
\hline Between populations within crop class ( $\Phi P R)$ & 2 & 0.183 & 6 & 0.057 & 0.001 \\
\hline Individuals within populations (ФРТ) & 249 & 2.986 & 90 & 0.094 & 0.001 \\
\hline
\end{tabular}

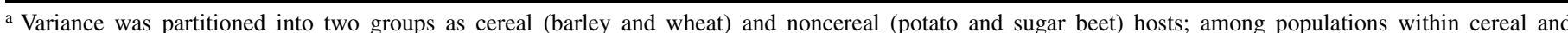
noncereal; and individuals within each four populations sampled from four crops.

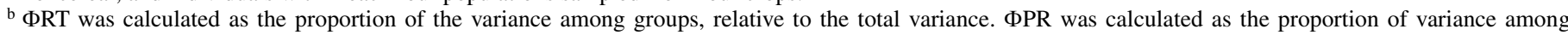
populations within groups, relative to the variance among and within populations. ФPT was calculated as proportion of variance among groups and populations of individuals, relative to the total variance (17).

c Probability of obtaining equal or lower $\Phi$ value was determined by 1,000 random permutations. Clone-corrected data were used for AMOVA. 
large numbers of strains in each wheat cultivar over time and space to test the hypothesis that sexual or clonal reproduction occurs among wheat cultivar subpopulations.

In this study, AMOVA revealed higher genetic variation among individuals within populations and wheat subpopulations as compared with genetic variation among populations or subpopulations. Previous studies $(15,18,20)$ essentially found similar results for $G$. zeae populations from wheat and authors concluded that recombination in the field may result in the creation of novel genotypes $(8,36)$, and thus, create potential for a rapid breakdown of disease resistance or development of fungicide resistance in the field. Our finding of higher genetic variation within populations indicates the prevalence of sexual reproduction, whereas higher genetic variation between populations indicates the prevalence of asexual reproduction. In the case of the sexual oomycete, Aphanomyces euteiches, which frequently selfs, higher genetic variation was found among populations as compared to within populations (22).

One of the important findings of this study was the minimal variation in the population structure of $G$. zeae between the cereal and noncereal populations. The low $D$ and high $\mathrm{Nm}$ values between populations from the four hosts were in line with the low genetic differentiation due to high levels of gene flow between $G$. zeae populations. Our data also indicate that G. zeae populations between potato and sugar beet had lowest $D$ and highest $\mathrm{Nm}$ values, showing that the two populations are genetically quite similar to each other. Furthermore, AMOVA also revealed low genetic variation between the cereal and noncereal populations and between populations within cereal or noncereal habitats. We hypothesize that $G$. zeae propagules from previous crop residues within a field or surrounding fields may play an important role in genetic exchange between cereal and noncereal populations. The high gene flow among subpopulations increases the genetic diversity and decrease genetic differentiation among them, thus, maintaining a large effective population (30). Zeller et al. (62) reported genetic exchange among $G$. zeae populations from wheat over large geographical distances in the United States. Similar results also were found by Schmale et al. (50) among the atmospheric populations of $G$. zeae in the United States, suggesting that the airborne ascospores of the fungus can travel long distances. Overall, our study suggests little or no role of these four crops in structuring of $G$. zeae populations in the upper Midwest of the United States.

Our results explain the relationship between host plant resistance and epidemiological observations in this biological system. The evidence of low Fst, $D$, and genetic variation between the resistant and susceptible wheat subpopulations demonstrated that the FHB resistant cultivars have low impact on the population differentiation of G. zeae. The inheritance of resistance to FHB in wheat is quantitative (34). In general, quantitative resistance is nonspecific and exerts low selection pressure on the pathogen population (58). The low $F$ st, $D$, and genetic variation between the two subpopulations may be due to low selection pressure on $G$. zeae populations as a result of the quantitative nature of FHB resistance in wheat cultivars. In contrast, Xia et al. (60) observed the strong influence of rice cultivars with known major gene resistance on the lineage exclusion of Magnaporthe grisea. The fungal strains collected from rice cv. Mars having $\mathrm{Pi}$ $z$, a major resistance gene for $M$. grisea, belonged to a distinct lineage.

FHB in cereals had been reported as early as the 1890s (5) while the fungus in potato and sugar beet has only been recently

TABLE 5. Genetic diversity and multilocus linkage disequilibrium analysis of Gibberella zeae subpopulations from 10 hard red spring wheat cultivars grown in North Dakota

\begin{tabular}{|c|c|c|c|c|c|}
\hline Subpopulation & $n^{\mathrm{a}}$ & $G^{\mathrm{b}}$ & $G D^{\mathrm{c}}$ & $H^{\mathrm{d}}$ & $\mathrm{LD}^{\mathrm{e}}$ \\
\hline \multicolumn{6}{|c|}{ Resistant subpopulation } \\
\hline Alsen & 36 & 25 & 0.976 & 0.510 & $0.090^{* * \mathrm{f}}$ \\
\hline Glenn & 28 & 22 & 0.981 & 0.561 & $0.070^{* *}$ \\
\hline Subtotal & 100 & 76 & & & \\
\hline \multicolumn{6}{|c|}{ Susceptible subpopulation } \\
\hline Briggs & 18 & 14 & 0.973 & 0.444 & $0.071^{* *}$ \\
\hline Dapps & 17 & 11 & 0.950 & 0.479 & $0.200 * *$ \\
\hline Knudson & 19 & 12 & 0.947 & 0.457 & $0.240^{* *}$ \\
\hline Norpro & 16 & 13 & 0.967 & 0.461 & $0.040^{*}$ \\
\hline Saturn & 22 & 14 & 0.935 & 0.457 & $0.050 *$ \\
\hline Subtotal & 127 & 93 & & & \\
\hline
\end{tabular}

a Sample size $(n)$.

${ }^{\mathrm{b}}$ Number of distinct genotypes $(G)$.

${ }^{\mathrm{c}}$ Genotypic diversity $(G D)$ within population was calculated as $G D=(n / n-1)\left(1-\sum p i^{2}\right)$, where $p i$ is the frequency of the $i$ th genotype, and $n$ is the number of individuals sampled (1).

${ }^{\mathrm{d}}$ Gene diversity $(H)(40)$ within population was calculated based on 10 variable number tandem repeat loci from clone-corrected data.

e The measure of multilocus linkage disequilibrium (LD) calculated from clone-corrected data (1).

$\mathrm{f} *$ and $* *$ indicate significant at $P<0.05$ and 0.01 , respectively.

TABLE 6. Analysis of molecular variance (AMOVA) for Gibberella zeae subpopulations from 10 hard red spring wheat cultivars grown in North Dakota during 2004 and 2005

\begin{tabular}{|c|c|c|c|c|c|}
\hline Hierarchical analysis ${ }^{\mathrm{a}}$ & df & Estimated variance & Variation $(\%)$ & $\Phi^{\mathrm{b}}$ & $P$ value ${ }^{\mathrm{c}}$ \\
\hline Between resistance classes $(\Phi R T)$ & 1 & 0.031 & 1 & 0.009 & 0.028 \\
\hline Among subpopulations within group (ФPR) & 8 & 0.527 & 17 & 0.169 & 0.001 \\
\hline Individual within subpopulations (ФРТ) & 159 & 2.596 & 82 & 0.176 & 0.001 \\
\hline
\end{tabular}

a Variance was partitioned into two groups (resistant and susceptible groups); among cultivar subpopulations within group; and among individuals within 10 cultivar subpopulations.

${ }^{\mathrm{b}}$ ФRT was calculated as the proportion of the variance among groups, relative to the total variance. ФPR was calculated as the proportion of variance among populations within group, relative to the variance among and within populations. ФPT was calculated as proportion of variance among groups and populations of individuals, relative to the total variance (17).

c Probability of obtaining equal or lower $\Phi$ value determined by 1,000 random permutations. Clone-corrected data were used for AMOVA. 
reported $(3,23)$. The importance of infected potato tubers or infected crop residues as inoculum sources in rotational cropping systems in this pathosystem is unclear. We hypothesize that the existing G. zeae populations from barley and wheat could have been adapted to potato and sugar beet due to the fitness ability of the fungus to survive in crop residues. In addition, cropping patterns such as overlapping growing seasons and rotations between cereal and noncereal crops may act as bridges for the fungus to infect noncereal hosts. Another hypothesis is that changes in cultivation practices of potato and sugar beet can make these crops more vulnerable to the fungus. For example, farm machineries during harvesting may increase bruises in the potato tubers and sugar beet roots, which may be a good infection avenue for G. zeae. In fact, G. zeae is a facultative parasite (26) and therefore, wounding or injury may be necessary to infect these traditional "nonhost" crops. Ecological and epidemiological factors that play important roles in the adaptation and survival of this fungus in the Upper Midwest of the United States need to be examined fully.

This study demonstrated the substantial genetic exchange among populations of $G$. zeae across cereal and noncereal hosts and across wheat cultivars. G. zeae populations from barley, wheat, potato, and sugar beet are genetically similar and could be part of a larger overall population. Our previous findings revealed that $G$. zeae populations from potato and sugar beet induced typical FHB symptoms in the susceptible wheat cultivar and produced different mycotoxins in wheat spikes and rice grain culture $(10,11)$. Overall, the findings of this study should provide insight into the comparative population biology of G. zeae from cereal and noncereal crops.

\section{ACKNOWLEDGMENTS}

We thank K. O'Donnell for providing representative strains of the $G$. zeae. We also thank R. Goswami, S. Mamidi, R. Lee, and J. B. Scott for their valuable suggestions in data analysis, M. Pull for editing the manuscript, and P. Burlakoti, R. Estrada Jr., and V. V. Rivera for their technical support. The first author was supported in part by the NDSU Graduate School Fellowship. This work was supported by the Agriculural Experiment Station, NDSU, and a cooperative project with the United States Wheat and Barley Scab Initiative, USDA under Agreement No. 590790-5-076. Any opinions, findings, conclusions, or recommendations exressed in this publication are those of the authors and do not necessarily reflect the view of the United States Department of Agriculture.

\section{LITERATURE CITED}

1. Agapow, P. M., and Burt, A. 2001. Indices of multilocus linkage disequilibrium. Mol. Ecol. Notes 1:101-102.

2. Akinsanmi, O. A., Backhouse, D., Simpfendorfer, S., and Chakraborty, S. 2006. Genetic diversity of Australian Fusarium graminearum and $F$. pseudograminearum. Plant Pathol. 55:494-504.

3. Ali, S., Rivera, V. V., and Secor, G. A. 2005. First report of Fusarium graminearum causing dry rot of potato in North Dakota. Plant Dis. $89: 105$.

4. Alstchul, S. F., Madden, T. L., Schäffer, A. A., Zhang, J., Zhang, Z., Miller, W., Lipman, D. J. 1997. Gapped BLAST and PSI-BLAST: A new generation of protein database search programs. Nucleic Acids Res. 25:3389-3402.

5. Arthur, J. C. 1891. Wheat scab. Purdue Univ. Agric. Exp. Stn. Bull. $36: 129-132$.

6. Bai, G., and Shaner, G. 1994. Scab of wheat: Prospects for control. Plant Dis. 78:760-766.

7. Bilgi, V. N., Bradley, C. A., Ali, S., Khot, S. D., and Rasmussen, J. B. 2007. Reaction of dry bean genotypes to root rot caused by Fusarium graminearum. (Abstr.) Phytopathology 97(suppl.):S10.

8. Bowden, R. L., and Leslie, J. F. 1999. Sexual recombination in Gibberella zeae. Phytopathology 89:182-188.

9. Broders, K. D., Lipps, P. E., Paul, P. A., and Dorrance, A. E. 2007. Evaluation of $F$. graminearum associated with corn and soybean seed and seedling disease in Ohio. Plant Dis. 97:1155-1160.

10. Burlakoti, R. R., Ali, S., Secor, G. A., Neate, S. M., McMullen, M. P., and Adhikari, T. B. 2007. Genetic diversity of $F$. graminearum populations from cereal and non-cereal hosts. Page 24 in: Proceedings of the National Fusarium Head Blight Forum. S. M. Canty, A. Clark, D. Ellis, and D. V. Sanford, eds. University of Kentucky, ASAP Printing Inc., Okemos, MI.

11. Burlakoti, R. R., Estrada, R., Jr., Rivera, V. V., Boddeda, A., Secor, G. A., and Adhikari, T. B. 2007. Real-time PCR quantification and mycotoxin production of Fusarium graminearum in wheat inoculated with isolates collected from potato, sugar beet and wheat. Phytopathology 97:835-841.

12. Corpet, C. 1988. Multiple sequence alignment with hierarchical clustering. Nucleic Acids Res. 16:10881-10890.

13. Demeke, T., Clear, R. M., Patrick, S. K., and Gaba, D. 2005. Speciesspecific PCR-based assays for the detection of Fusarium species and a comparison with the whole seed agar plate method and trichothecene analysis. Int. J. Food Microbiol. 103:271-284.

14. D’Mello, J. P. F., Plancinta, C. M., and Macdonald, A. M. C. 1999. Fusarium mycotoxins: A review of global implications for animal health, welfare and productivity. Anim. Feed Sci. Technol. 80:183-205.

15. Dusabenyagasani, M., Dostaler, D., and Hamelin, R. C. 1999. Genetic diversity among Fusarium graminearum strains from Ontario and Quebec. Can. J. Plant Pathol. 21:308-314.

16. Estrada, R., Jr., Rivera, V. V., and Secor, G. A. 2007. Pathogenicity of Fuarium graminearum to potato, sugar beet and wheat. (Abstr.) Phytoathology 97(suppl.):S160.

17. Excoffier, L., Smouse, P. E., and Quattro, J. M. 1992. Analysis of molecular variance inferred from metric distances among DNA haplotype: Application to human mitochondrial DNA restriction sites. Genetics 131:479-491.

18. Fernando, W. G. D., Zhang, J. X., Dusabenyagasani, M., Guo, X. W., Ahmed, H., and McCallum, B. 2006. Genetic diversity of Gibberella zeae isolates from Manitoba. Plant Dis. 90:1337-1342.

19. Frohberg, R. C., Stack, R. W., Olson, T., Miller, J. D., and Mergoum, M. 2006. Registration of Alsen wheat. Crop Sci. 46:2311-2312.

20. Gale, L. R., Chen, L.-F., Hernick, C. A., Takamura, K., and Kistler, H. C. 2002. Population analysis of Fusarium graminearum from wheat fields in eastern China. Phytopathology 92:1315-1322.

21. Gale, L. R., Ward, T. J., Balmas, V., and Kistler, H. C. 2007. Population subdivision of Fusarium graminearum Sensu Stricto in the upper midwestern United States. Phytopathology 97:1434-1439.

22. Grünwald, N. J., and Hoheisel, G. A. 2006. Hierarchical analysis of diversity, selfing, and genetic differentiation in populations of the oomycete Aphanomyces euteiches. Phytopathology 96:1134-1141.

23. Hanson, L. E. 2006. Fusarium yellowing of sugar beet caused by Fuarium graminearum from Minnesota and Wyoming. Plant Dis. 90:686.

24. Komada, H. 1975. Development of a selective medium for quantitative isolation of Fusarium oxysporum from natural soils. Rev. Plant Prot. Res. 8:114-125.

25. Large, E. C. 1954. Growth stages in cereals. Illustrations of the Feekes scale. Plant Pathol. 3:128-129.

26. Liddel, C. M. 2003. Systematics of Fusarium species and Allies associated with Fusarium head blight. Pages 35-43 in: Fusarium Head Blight of Wheat and Barley. K. J. Leonard and W. R. Bushnell, eds. The American Phytopathological Society, St. Paul, MN.

27. Lunt, D. H., Whipple, L. E., and Hyman, B. C. 1998. Mitochondrial DNA variable number tandem repeats (VNTRs): Utility and problems in molecular ecology. Mol. Ecol. 7:1441-1455.

28. Marasas, W. F. O., Nelson, P. E., and Toussoun, T. A. 1984. Toxigenic Fusarium species: Identity and Mycotoxicology. The Pennsylvania State University Press, University Park.

29. Markell, S. G., and Francl, L. J. 2003. Fusarium head blight inoculum: Species prevalence and Gibberella zeae spore type. Plant Dis. 87:814-820.

30. McDermott, J. M., and McDonald, B. A. 1993. Gene flow in plant pathosystems. Annu. Rev. Phytopathol. 31:353-373.

31. McDonald, B. A., and McDermott, J. M. 1993. Population genetics of plant pathogenic fungi. Bioscience 43:311-319.

32. McMullen, M., Jones, R., and Gallenberg, D. 1997. Scab of wheat and barley: A re-emerging disease of devastating impact. Plant Dis. 81:3401348.

33. Mergoum, M., Frohberg, R. C., and Stack, R. W. 2007. Breeding hard red spring wheat for Fusarium head blight resistance, successes and challenges. Pages 161-167 in: Wheat Production in Stressed Environents, vol. 12. H. T. Buck, J. E. Nisi, and N. Salomón, eds. Springer, Netherlands.

34. Mesterhazy, A., Bartok, T., Mirocha, C. G., and Komoroczy, R. 1999. Nature of wheat resistance to Fusarium head blight and the role of deoxynivalenol for breeding. Plant Breed. 118:97-110.

35. Miedaner, T., Schilling, A. G., and Geiger, H. H. 2001. Molecular genetic diversity and variation for aggressiveness in populations of Fusarium graminearum and Fusarium culmorum sampled from wheat fields in different countries. J. Phytopathol. 149:641-648.

36. Milgroom, M. G. 1996. Recombination and the multilocus structure of fungal populations. Annu. Rev. Phytopathol. 34:457-477. 
37. Milgroom, M. G., and Lipari, S. E. 1995. Population differentiation in the chestnut blight fungus, Cryphonectria parasitica, in eastern North America. Phytopathology 85:155-160.

38. Mishra, P. K., Tewari, J. P., Clear, R. M., and Turkington, T. K. 2004. Molecular genetic variation and geographical structuring in Fusarium graminearum. Ann. Appl. Biol. 145:299-307.

39. Nei, M. 1973. Analysis of gene diversity in subdivided populations. Proc. Natl. Acad. Sci. USA 70:3321-3323.

40. Nei, M. 1978. Estimation of average heterozygosity and genetic distance from a small number of individuals. Genetics 89:83-590.

41. Nelson, P. E., Toussoun, T. A., and Marasas, W. F. O. 1983. Fusarium species: An Illustrated Manual for Identification. Pennsylvania State University Press, University Park, Pennsylvania.

42. Nganje, W. E., Bangsund, D. A., Leistritz, F. L., Wilson, W. W., and Tiapo, N. M. 2004. Regional economic impacts of Fusarium head blight in wheat and barley. Rev. Agric. Econ. 26:332-347.

43. Nicholas, K. B., Nicholas, H. B., Jr., and Deerfield, D. W., II. 1997 GeneDoc: Analysis and visualization of genetic variation. Embnew. News $4: 14$.

44. Nicholson, P., Simpson, D. R., Weston, G., Rezanoor, H. N., Lees, A. K., Parry, D. W., and Joyce, D. 1998. Detection and quantification of Fusarium culmorum and Fusarium graminearum in cereals using PCR assays. Physiol. Mol. Plant Pathol. 53:13-17.

45. O'Donnell, K., Kistler, H. C., Tacke, B. K., and Casper, H. H. 2000. Gene genealogies reveal global phylogeographic structure and reproductive isolation among lineages of Fusarium graminearum, the fungus causing wheat scab. Proc. Natl. Acad. Sci. USA 97:7905-7910.

46. O'Donnell, K., Ward, T. J., Geiser, D. M., Kistler, H. C., and Aoki, T. 2004. Genealogical concordance between the mating type locus and seven other nuclear genes supports formal recognition of nine phylogenetically distinct species within the Fusarium graminearum clade. Fungal Genet. Biol. 41:600-623.

47. Parry, D. W., Jenkinson, P., and McLeod, L., 1995. Fusarium ear blight (scab) in small grain cereals-A review. Plant Pathol. 44:207-238.

48. Peakall, R., and Smouse, P. E. 2006. GENALEX 6: Genetic analysis in Excel. Population genetic software for teaching and research. Mol. Ecol. Notes 6:288-295

49. Ransom, J. K., Sorenson, B., and Mergoum, M. 2006. North Dakota hard red spring wheat variety trial results for 2006 and selection guide. NDSU Extension Service, NDSU. A-574 (revised).
50. Schmale, D. G., III, Leslie, J. F., Zeller, K. A., Saleh, A. A., Shields, E. J., and Bergstrom, G. C. 2006. Genetic structure of atmospheric populations of Gibberella zeae. Phytopathology 96:1021-1026.

51. Shi, J., Ward, R., Wang, D., and Lewis, J. 2001. Application of a high throughput, low cost, non-denaturing polyacrylamide gel system for wheat microsatellite mapping. Pages 25-30 in: National Fusarium Head Blight Forum. M. Canty, J. Lewis, L. Silver, and R. W. Ward, eds. Kinko's Publisher, Okemos, MI.

52. Slatkin, M. 1987. Gene flow and geographic structure of natural popuations. Science 236:787-792.

53. Stack, R. W., and McMullen, M. 1985. Head blighting potential of Fusarium species associated with spring wheat heads. Can. J. Plant Pathol. 7:79-82.

54. Staden, R. 1994. The Staden package. Pages 9-170 in: Methods in Molecular Biology, Vol. 25. A. M. Griffin and H. G. Griffin, eds. Humana Press, Totowa, NJ.

55. Suga, H., Gale, L. R., and Kistler, H. C. 2004. Development of VNTR markers for two Fusarium graminearum clade species. Mol. Ecol. Notes 4:468-470.

56. Swofford, D. L. 2002. PAUP*. Phylogenetic analysis using parsimony (*and other methods) Version 4.0b10. Sinauer Associates, Sunderland, MA.

57. U.S. Dep. Agric.-NAAS. 2007. North Dakota 2007 Wheat Varieties, June 2007 Report. National Agricultural Statistics Service, North Dakota Field Office, Fargo, ND.

58. Vanderplank, J. E. 1968. Disease Resistance in Plants. Academic Press, New York.

59. Walker, S. L., Leath, S., Hagler, W. M., Jr., and Murphy, J. P. 2001. Variation among isolates of Fusarium graminearum associated with Fusarium head blight in North Carolina. Plant Dis. 85:404-410.

60. Xia, J. Q., Correll, J. C., Lee, F. N., Ross, W. J., and Rhoads, D. D. 2000. Regional population diversity of Pyricularia grisea in Arkansas and the influence of host selections. Plant Dis. 84:877-884.

61. Yeh, F. C., Yang, R.-C., Boyle, T. B. J., Ye, Z.-H., and Mao, J. X. 1997. POPGENE, the user-friendly shareware for population genetic analysis. Molecular Biology and Biotechnology Center, University of Alberta, Canada.

62. Zeller, K. A., Bowden, R. L., and Leslie, J. F. 2004. Population differentiation and recombination in wheat scab populations of Gibberella zeae from the United States. Mol. Ecol. 13:563-571. 